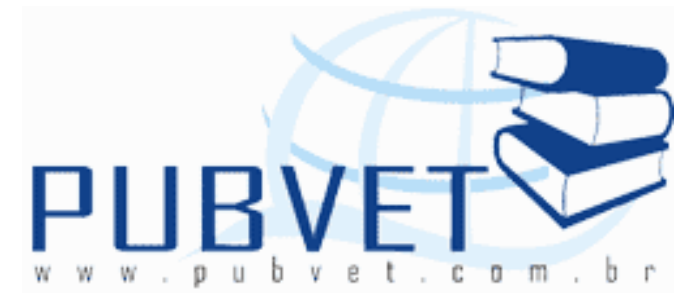

PUBVET, Publicações em Medicina Veterinária e Zootecnia.

\title{
Efeito do estresse térmico sobre os parâmetros fisiológicos e bioquímicos de ovinos criados em clima tropical
}

Flávio de Sousa Oliveira ${ }^{1}$, Vicente de Paula Fernandes Neto ${ }^{2}$, Marinna Nérica do Nascimento e Silva ${ }^{1}$, Francimarne Sousa Cardoso ${ }^{1}$, Amilton Paulo Raposo Costa $^{3}$

${ }^{1}$ Méd. Vet., Doutorandos em Ciência Animal, Universidade Federal do Piauí Autor para contato: sousasoft@hotmail.com

2 Méd. Vet., Mestrando em Ciência Animal, Universidade Federal do Piauí

${ }^{3}$ Docente no Depto. de Morfofisiologia Veterinária/CCA/UFPI.

\section{Resumo}

Em regiões tropicais e sub-tropicais, uma elevada temperatura ambiente é o principal fator que compromete a produtividade animal, este efeito é agravado quando estresse calórico ocorre em ambientes com alta umidade. A exposição de ovinos às temperaturas elevadas resulta em diminuição do peso corporal, do ganho de peso médio diário e taxa de crescimento corporal, e na sua atividade reprodutiva. Os mecanismos envolvidos na dissipação desse calor em excesso são o evaporativo onde a evaporação da água do trato respiratório e superfície da pele através da respiração ofegante e transpiração, que permite a perda de calor através das propriedades fisioquímicas da água. A despeito disto a carência de água em regiões tropicais agrava ainda mais o processo de estresse por calor. O estresse térmico induz a uma série de mudanças nas 
funções biológicas, que incluem uma diminuição na eficiência de consumo de ração e utilização, desequilíbrios hídrico, protéico, energético e mineral, alem de alterações nas reações enzimáticas, secreções hormonais e metabólitos do sangue. Estudos recentes indicam que o núcleo supraquiasmático (SCN) regula o ritmo circadiano e sazonal da maioria das funções biológicas, em particular as funções de reprodução e comportamento em mamíferos. O essencial na produção ovina é desenvolver raças bem adaptadas às diferentes localidades para que possam expressar ao máximo o seu potencial genético.

Palavras-chave: Estresse térmico, Ovinos, Parâmetros fisiológicos.

\title{
Effect of heat stress on physiological and biochemical parameters of sheep raised in tropical climate
}

\begin{abstract}
In tropical and sub-tropical high temperature is the main factor that affects animal productivity, this effect is compounded when heat stress occurs in environments with high humidity. Exposure to elevated temperatures sheep results in decreased body weight, the average daily weight gain, growth rate body, and in their reproductive activity. The mechanisms involved in the dissipation of excess heat is the evaporative where the evaporation of water from the respiratory tract and the skin surface by means of breath and perspiration, allowing the heat loss through the physio-chemical properties of water. Despite this lack of water in tropical regions further aggravates the process of heat stress. Heat stress induces a series of changes in biological functions, including a decrease in efficiency of feed intake and utilization, fluid imbalances, protein, energy and mineral, in addition to changes in enzymatic reactions, hormonal secretions and blood metabolites. Recent studies indicate that the suprachiasmatic nucleus (SCN) regulating the circadian and seasonal of most biological functions, in particular the functions of reproduction and behavior in mammals. The key is to develop the production of sheep breeds
\end{abstract}


are well adapted to different locations so they can express the most of your genetic potential.

Keywords: Heat stress, Sheep, Physiological parameters.

\section{Introdução}

O rebanho ovino do Nordeste é expressivamente representativo e um importante fator na sustentabilidade da ovinocultura da região, e subsistência dos criadores de baixa renda. Tornando-se um potencial econômico significativo. Embora numericamente expressivo, esse rebanho apresenta níveis acentuadamente reduzidos de desempenho (GUIMARÃES FILHO et al., 2000). São entraves para a produção desses animais os sistemas de criação onde predomina o extensivo, aliado a isso, os elementos climáticos como temperaturas altas.

O calor é uma limitação importante sobre a produtividade animal no cinturão tropical e regiões áridas (SILANIKOVE, 1992). O Brasil possui grande maioria do seu território, cerca de dois terços, situado na faixa tropical do planeta, onde predominam altas temperaturas do ar, conseqüência da elevada radiação solar incidente (PIRES et al., 2000), o que provoca o chamado estresse térmico (MARTELLO et al., 2004) e essas condições climáticas adversas pode afetar a produção nos mais variados níveis (JOCA et al., 2003).

Além dos fatores ambientais que interferem no equilíbrio térmico dos animais, o pelame exerce uma importância fundamental para as trocas térmicas entre o organismo e o ambiente. A estrutura física da capa de pêlos e a camada de ar nela armazenada promovem isolamento térmico e proteção contra a radiação solar direta (SILVA, 2000).

Nesta revisão os caracteres fisiológicos, morfológicos e bioquímicos influenciáveis pelo estresse calórico são destacados.

\section{2. Índices de estressor térmico}

Os animais do semi-árido Brasileiro são mantidos a maior parte do ano em pastagens nativas, insuficientes para suprir suas necessidades nutricionais. 
Aliado a isso o ambiente térmico, representado pela temperatura, umidade relativa e velocidade do ar e radiação solar, afetam diretamente o animal. Em trabalho com cordeiros constatou-se que o peso corporal dos animais observado nas diferentes fases do crescimento foi considerado muito baixo, quando comparado com o desenvolvimento de ovinos de clima temperado. Isso revela que problemas de temperatura e alimentação podem ser considerados como fatores essenciais (FERNANDES et al. 2001). Portanto a formulação de escalas de temperatura fisiológica é importante para delinear um espaço climático apropriado ou uma raça ou espécie (FINCH, 1984).

Para a caracterização térmica do ambiente, propõem-se a determinação de índices climáticos calculados a partir da mensuração da temperatura ambiente e a umidade relativa do ar à sombra. Índices de estresse de calor vão de uma simples medição da temperatura do ar a índices que tentam fornecer uma estimativa ponderada desses fatores.

Originalmente desenvolvido por Thom (1958) como um índice de conforto térmico humano, o ITU (índice de temperatura e umidade) foi proposto com um meio de estimar a o potencial estressante do ambiente usando também o efeito combinado da temperatura ambiente e umidade do ar ou temperatura de ponto de orvalho (SILVA, 200). A equação que determina o ITU, conforme Benício \& Sousa (2001) é a seguinte:

\section{ITU1 $=0,72($ Tbs + Tbu $)+40,6$}

Em que Tbs corresponde à temperatura do bulbo seco, em graus ${ }^{\circ} \mathrm{C}$., e Tbu a temperatura do bulbo úmido em percentual (\%). Valores do ITU até 70 mostra uma condição normal; valores de 71 a 78 indicam uma condição critica, de 79 a 83 existe um perigo e acima de 83 uma condição de emergência (HAHN, 1985 E BARBOSA \& SILVA, 1995),. Segundo MacDowell et al. (1996) valores superiores a 78 causam sofrimento extremo e os animais são incapazes de manter os mecanismos de termorregulação, ou temperatura corporal normal. Lemerle \& Goddard (1986) relataram que, embora a 
temperatura retal só tenha aumentado quando THI foi superior a 80 , a freqüência respiratória só aumentou com THI de 73 e, acentuando-se acima de 80. Este achado sugere que mecanismos homeostáticos, incluindo aumento da respiração, podem impedir um aumento da temperatura retal até o THI chegar a 80. Isso é semelhante ao nível crítico de 78 THI citado por McDowell et al. (1976).

Outro índice utilizado para predizer o ambiente estressante para os animais é o índice da temperatura do globo negro e umidade do ar (ITGU) sugerido por Buffingtom et al. (1981). Este índice foi desenvolvido para vacas leiteiras criadas a pasto e leva em consideração a radiação térmica, fator ambiental importante para os animais criados nestas condições e, representa, provavelmente, um dos melhores índices para representar o estresse térmico em áreas abertas. Uma critica ao ITU é que ele não leva em consideração o fator radiação, extremamente importante para animais em espaços abertos. Baseado nesse aspecto, o autor introduziu uma modificação na equação do ITU, substituindo a temperatura do ar pela temperatura de globo negro:

\section{$\mathrm{ITGU}=\mathrm{T}_{\mathrm{G}}+0,36 \mathrm{Tpo}+41,5$}

Entretanto, a temperatura indicada pelo globo negro reflete a ação específica da radiação e da velocidade do vento sobre uma esfera metálica geralmente de $15 \mathrm{~cm}$ de diâmetro. Se for usado um globo de diâmetro diferente nas mesmas condições, a resposta aos fatores ambientais também será diferente e, portanto, outra será a temperatura $\mathrm{T}_{\mathrm{G}}$. Em outras palavras, a temperatura do globo expressa à ação do ambiente radiante sobre um globo especifico e não pode descrever de uma forma geral a ação sobre um animal.

Um índice destinado à classificação de ambientes para criação de ovinos das raças Corriedale, Suffolk e Ideal, proposto por Silva e Barbosa (1993) é o Índice de Conforto Térmico para Ovinos (ITC): 
Onde $P_{V}$ é a pressão parcial de vapor do ar $(\mathrm{kPa})$ e $T_{G}$ a temperatura de globo negro $\left({ }^{\circ} \mathrm{C}\right)$. Esse índice agrega, em sua fórmula, os quatro elementos ambientais que mais influenciam o desempenho animal: temperatura $\mathrm{e}$ umidade do ar, radiação térmica e velocidade do vento, e constataram que o ICT é mais fortemente correlacionado com a temperatura retal (TR) e frequência respiratória (FR) dos animais que o índice temperatura globo e umidade (ITGU) e o índice de temperatura e umidade (ITU). Foi utilizado posteriormente para a determinação do zoneamento bioclimático da ovinocultura nos estados de São Paulo e Paraná (BARBOA et al. 1995).

Estudando animais Santa Inês de diferentes pelagens, Neves et al. (2009) baseando-se na frequência respiratória concluíram que o valor crítico do Índice de Conforto Térmico foi de 38,0 para os animais das três cores, valor esse que pode ser utilizado pelos criadores de ovinos da raça Santa Inês, no agreste de Pernambuco, como referência para se definir o estresse pelo calor nos seus animais.

\section{Zona de Termoneutralidade}

As variáveis ambientais são os fatores estressantes, os quais agem sobre o organismo como um todo, levando-o a reagir de alguma forma e os resultados dessa reação podem ser avaliados através do comportamento das variáveis fisiológicas, cujo conjunto dá uma medida da tensão ocorrente. Evidentemente, é impraticável a tomada de decisões a respeito do manejo dos animais, por exemplo, com base nas medidas isoladas das características morfológicas e das variáveis fisiológicas, em um determinado ambiente (SILVA, 2005).

Cada espécie animal possui uma faixa de temperatura de conforto, a zona termoneutralidade, definida como a faixa de temperatura em que a produção é ótima e o gasto de energia para termorregulação é mínimo (fig.1). Esta varia com a taxa metabólica e a quantidade de isolamento de cada animal.

$\mathrm{Na}$ zona de termoneutralidade (ZTN), a temperatura corpórea pode ser regulada por mecanismos vasomotores que aumentam ou diminuem o fluxo 
sanguíneo cutâneo e, consequentemente, alteram a quantidade de perda de calor por convecção e irradiação (CUNINNGAN, 2008).

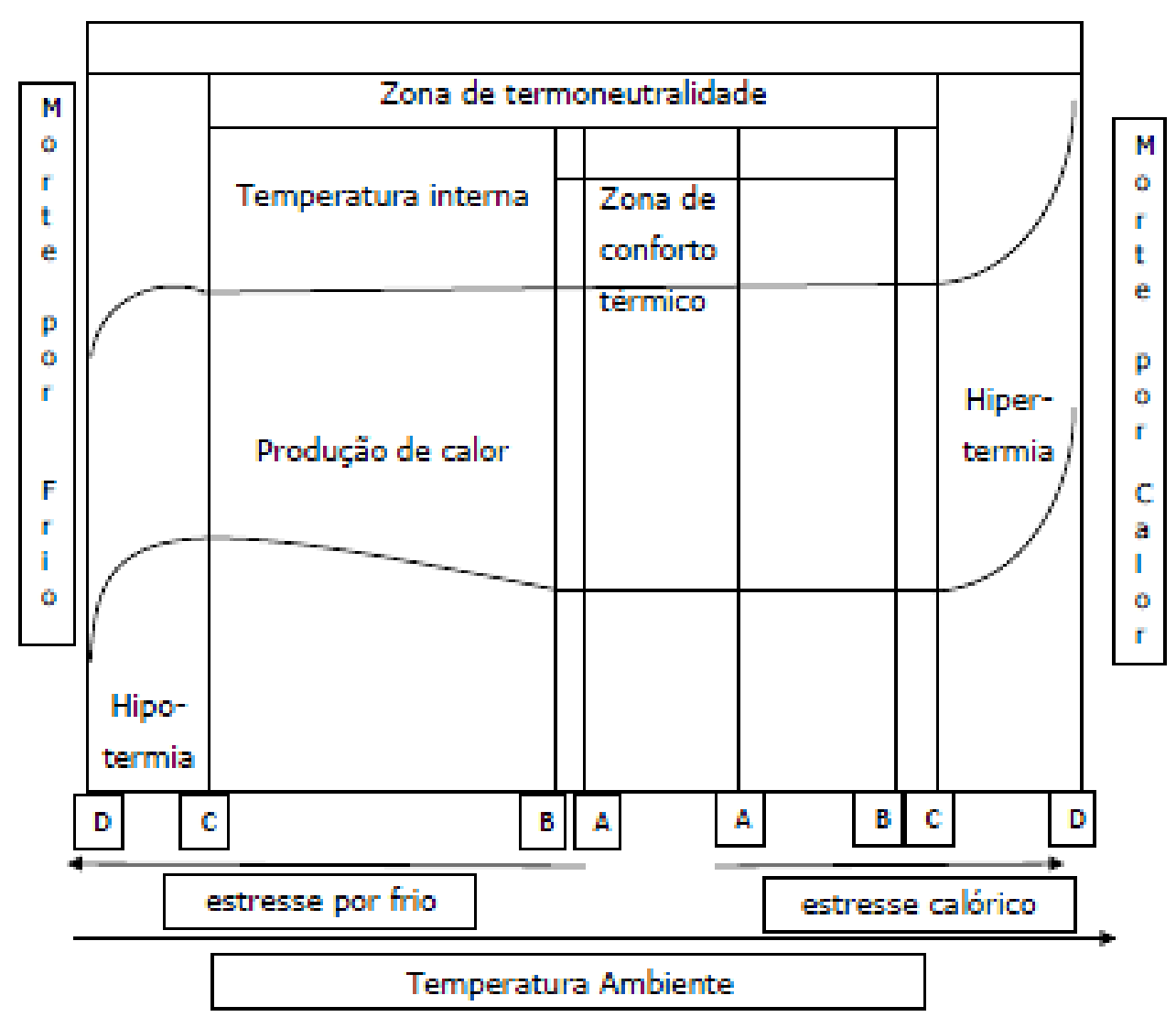

Figura 1. Apresentação esquemática das zonas de termoneutralidade e homeotermia no que diz respeito às condições ambientais em ruminantes. Adaptado de Hafez (1973).

Uma definição adequada da zona de conforto térmico pode ser indicada como sendo a faixa de temperatura ambiente em que a taxa metabólica é mínima e a homeotermia é mantida com menor gasto energético (CURTO et al.2007). Na zona de conforto térmico a fração de energia metabolizável utilizada para termogênese é mínima e a energia líquida de produção é máxima. Aos limites superior e inferior desta zona, dá-se o nome de temperatura crítica superior e temperatura crítica inferior (FIALHO, 2001). No entanto, embora a definição do menor ponto crítico seja precisa e inequívoca, 
o ponto crítico superior pode ser definido de várias maneiras (MOUNT, 1973). A temperatura ambiente abaixo da qual a taxa de produção de calor de um homeotermo aumenta para manter o equilíbrio térmico, é a temperatura crítica inferior. A temperatura crítica superior pode ser definida como a temperatura ambiente quando: (a) aumenta a taxa metabólica, (b) aumenta a perda de calor por evaporação, ou (c) o isolamento térmico do tecido é mínimo.

Dentro de ampla faixa de temperatura, podem ser definidas zonas térmicas que proporcionam maior ou menor conforto ao animal. Os animais, para terem máxima produtividade, dependem de uma faixa de temperatura adequada, também chamada de zona de conforto térmico, em que não há gasto de energia ou atividade metabólica para aquecer ou esfriar o corpo (NEIVA et al., 2004).

De um modo geral, a especificação do ambiente com respeito aos animais tem sido baseada exclusivamente na temperatura do ar. Vários são os esforços aplicados na determinação das temperaturas que limitam a faixa de conforto para os animais domésticos, a temperatura crítica inferior (TCI) e a temperatura crítica superior (TCS), sendo os valores mais considerados os apresentados na Tabela 1.

Tabela 1. Valores médios em graus centígrados $\left({ }^{\circ} \mathrm{C}\right)$ de temperaturas ambientais críticas e faixas de conforto térmico para ovinos. Adaptado de Hahn (1985)

\begin{tabular}{l|c|c|c}
\hline \multicolumn{1}{c|}{ Categoria } & TCI & TCS & Faixa Ideal \\
\hline Adulto (velo normal) & -15 & 32 & $5-15$ \\
Adulto (tosquiado) & 18 & 30 & $22-25$ \\
Cordeiro ate 2 semanas & 12 & 33 & $27-30$ \\
Cordeiro em crescimento & -13 & 25 & $8-18$ \\
\hline
\end{tabular}

TCI - temperatura crítica inferior / TCS - temperatura crítica superior 


\section{Comportamento termorregulador}

Um organismo é dito em homeostase quando seu meio interno contém concentrações apropriadas de substâncias químicas e mantém a temperatura e a pressão adequadas (GUYTON, 2006). E seus sistemas fisiológicos operam normalmente com o intuito de reduzir a variação e manter, assim, a constância das funções internas do organismo (GOLDBERGER et al., 2002)

A homeotermia é mantida igualando a quantidade de calor produzida no metabolismo mais o calor absorvido do ambiente, com o fluxo de calor dissipado do animal para o ambiente. O fluxo de calor ocorre através de processos que dependem da temperatura ambiental (condução, convecção e radiação) e da umidade (evaporação via transpiração e respiração). A hipertermia ocorre quando o fluxo de calor para o ambiente é menor que a produção de calor metabólico somado ao calor recebido do ambiente.

Nos ambientes tropicais, a temperatura do ar tende a ser próxima ou ser maior que a corporal, o que torna ineficazes os mecanismos de transferência térmica por condução e convecção. Em adição, a carga térmica radiante é freqüentemente muito elevada, de modo que a superfície corporal dos animais tende a apresentar temperaturas bastante altas, dependendo da natureza dessa superfície (SILVA et al., 2003).

Dos animais domésticos, o ovino é um dos que apresentam mecanismos anatomofisiológicos mais propícios à sobrevivência em regiões de altas temperaturas, desde que a umidade do ar seja baixa.

Quando expostos a um ambiente térmico, no qual a produção excede a eliminação de calor, todas as fontes que geram calor endógeno são inibidas, principalmente o consumo de alimentos e o metabolismo basal e energético, enquanto a temperatura corporal, a freqüência respiratória e a taxa de sudação aumentam. Essas funções indicam tentativas do animal de minimizar o desbalanço térmico para manter a homeotermia (YOUSEF, 1985; SOTA et al., 1996). 


\subsection{Parâmetros fisiológicos}

A temperatura ambiente representa a principal influência climatológica sobre as variáveis fisiológicas temperatura retal (TR) e freqüência respiratória (FR) (SOUZA, 2005) e seguida em ordem de importância pela radiação solar, a umidade relativa do ar e o movimento do ar (LEE et al. 1974). Também tem sido objeto de estudo a freqüência cardíaca $(F C)$ e os constituintes sangüíneos (BIRGEL JúNIOR et al., 2001).

A temperatura retal e a freqüência respiratória são consideradas as melhores variáveis fisiológicas para estimar a tolerância de animais ao calor (BIANCA \& KUNZ, 1978; SOUZA et al, 2005).

\subsubsection{Freqüência Respiratória (FR)}

A avaliação da FR auxilia no estudo da capacidade do animal em resistir aos rigores do estresse calórico (MULLER et al., 1994). Quando os animais homeotérmicos são submetidos a ambientes de temperatura elevada, aumentam o ritmo respiratório, para auxiliar no processo de dissipação de calor, pode ocorrer de duas formas: 1) aquecimento do ar inspirado; 2) evaporação através das vias respiratórias (QUATERMAIN e BROANBENT, 1974; BACCARI JÚNIOR, 1990; SOUZA et al., 1990).

Segundo Silanikove (2000), a taxa de respiração pode quantificar a severidade do estresse pelo calor em ruminantes. Assim, uma FR de 40-60; 60-80 e 80-120 mov. min. ${ }^{-1}$ caracterizam, respectivamente, estresse baixo, médio-alto e alto, e acima de $200 \mathrm{mov} . / \mathrm{min}^{-1}{ }^{-}$o estresse seria severo em ovinos.

$\mathrm{Na}$ literatura, o que se encontra acerca da importância relativa da evaporação respiratória e da cutânea nos ovinos é evidencias conflitantes. Alguns autores mais antigos (RIECK 1950; KNAPP \& ROBINSON, 1954; BROOK \& SHORT, 1960) afirmam que, sob altas temperaturas (30 a $40^{\circ} \mathrm{C}$ ), a evaporação cutânea chega a ser até três vezes mais intensa que a respiratória. Outros supõem que a evaporação respiratória seja mais importante (ALEXANDER \& WILLIAMS, 1962; HOFMEYR ET AL., 1969; HALES, 1974). 
Cezar et al. (2004) avaliando animais Dorper, Santa Inês e seus mestiços no semi-árido nordestino verificaram que a freqüência respiratória, nesta pesquisa, foi significativamente maior $(P<0,05)$ durante o turno da tarde do que no turno da manhã. O mesmo resultado foi encontrado em caprinos por Santos et al. (2005) e Souza et al. (2005) onde eles afirmam que a temperatura retal e Frequência respiratória são influenciadas pelo período do dia.

Avaliando ovinos Santa Inês submetidos a duas dietas diferentes constatou-se que a freqüência respiratória dos animais mantidos à sombra e alimentados com dietas com alto teor de ração concentrada foi superior $(P<0,05)$ à freqüência respiratória daqueles alimentados com dietas contendo baixo teor de ração concentrada em ambos ambientes estudados. Os animais mantidos ao sol apresentaram os maiores valores de freqüência respiratória durante a tarde, independentemente do teor de ração concentrada da dieta, resultado justificado pela alta carga calórica recebida durante o dia (NEIVA et al., 2004).

Oliveira (2007) concluiu com base na freqüência respiratória que os animais Dorper e SPRD mantiveram sua homeotermia mesmo estando submetidos a uma zona fora do conforto térmico.

\subsubsection{Temperatura retal (TR)}

A TR é a medida que melhor representa a temperatura do núcleo central, sendo muito utilizada como critério de diagnóstico de doenças e para verificar o grau de adaptabilidade dos animais domésticos (BACCARI JÚNIOR, 1990; SOUZA et al., 2005). Um aumento na temperatura retal significa que o animal está estocando calor, e se este não é dissipado, o estresse calórico manifestase.

Segundo Silva (2000), considera-se hipertérmico o animal que apresenta temperatura corporal maior que a média do lote mais um desvio-padrão.

Assim como o efeito da temperatura ambiente influencia nos valores da temperatura retal, Neves et al. (2009) avaliando a correlação do TCI com a 
Temperatura retal (TR) constataram que $50 \%$ das variações ocorridas na TR estava relacionada com a cor da pelagem. Assim, o impacto dos elementos climáticos foi maior sobre os ovinos castanhos e pretos que nos brancos, sugerindo melhor controle da homeotermia nesses últimos em condições de maior desconforto térmico.

Em estudos com ovinos de diferentes raças foi verificado que, apesar da Temperatura retal estar dentro da faixa de normalidade fisiológica, houve diferença entre os horários da manha e da tarde com valores mais altos no turno da tarde (CEZAR, et. al., 2004; NEIVA et. al., 2004; OLIVEIRA 2007).

\subsubsection{Freqüência cardíaca}

Segundo Silva \& Gondim (1971), a FC está sujeita a um grande número de fatores, além da temperatura ambiente, como a idade, individualidade, temperamento e o grau de excitação do animal. A magnitude das variações depende de cada animal, pois as respostas ao estresse são diferentes quando comparados animais distintos; porém, trabalhos realizados com bovinos da raça Sindi (KELLY, 1976), demonstraram uma maior FC no verão.

A Frequência cardíaca dos animais domésticos apresenta grande variação sob diferentes testes de tolerância térmica e entre diferentes grupos genéticos (SINGH e BHATTACHARYYA, 1990), provavelmente porque, segundo Johnson et al. (1991) e Elvinger et al. (1992), o estresse térmico pode causar concentração do plasma sanguíneo, ou não ter nenhum efeito sobre seu volume. Todavia, uma freqüência cardíaca reduzida é mais típica em animais sob estresse térmico e está associada com uma taxa reduzida de produção de calor em resposta a temperaturas ambientais elevadas (KADZERE et al., 2002).

Cezar et al. (2004) verificaram em sua pesquisa que a freqüência de batimentos cardíacos registrada foi influenciada significativamente $(P<0,05)$ pelo turno, sendo a taxa cardíaca vespertina $(115,30 \mathrm{mov} . / \mathrm{min}$.) superior à taxa matutina (105,67mov./min.), o que contraria a hipótese de Kadzere et al. (2002), e os resultados encontrados por Souza et al. (2005). Esses resultados, 
embora sejam inferiores aos 126,4, para o período da manhã, e 133,2 mov./min., para o período da tarde, alcançados por Santos et al. (2003), são concordantes no que tange à superior idade da taxa vespertina sobre a matutina.

\section{Temperatura da pele}

A lã deve ser encarada como um isolante térmico, com a função de proteger os animais dos efeitos da intensa radiação solar. As raças mais especializadas para produção de lã, denominadas raças de lã fina, são justamente as que melhor se adaptam às condições de altas temperaturas, considerando que seu velo fino e denso representa uma barreira à transmissão de calor para a superfície corporal do animal (SIQUEIRA, 1990).

É sabido que os ovinos possuem glândulas sudoríparas do tipo apócrino, associadas aos folículos pilosos primários de lã (BLIGH, 1961; ROBERTSHAW, 1966) e alguns autores, como Brook \& Short (1960a,b) e Alexander \& Williams (1962), determinaram altas taxas de sudação em animais tosquiados mantidos a $40^{\circ} \mathrm{C}$. Silva et al. (1990) observaram animais da raça Ideal sob temperaturas entre 25 e $46^{\circ} \mathrm{C}$, determinando uma taxa de sudação média de $90,5 \pm 5,5 \mathrm{~g} \cdot \mathrm{m}^{-}$ ${ }^{2} h^{-1}$. Por outro lado, foi sugerido por Brockway et al. (1965) que, em animais cobertos de velo espesso submetidos a altas temperaturas em câmaras climáticas, as perdas térmicas por evaporação respiratória seriam mais importantes que as cutâneas, alcançando $0,84 \mathrm{~W} \cdot \mathrm{kg}^{-1}$ a $30^{\circ} \mathrm{C}$. Hofmeyr et al. (1969) observaram que em ovinos não tosquiados expostos por duas horas a $38^{\circ} \mathrm{C}$ a evaporação respiratória constituía $65 \%$ da perda evaporativa total.

No que se refere à influência da espessura do velo, é interessante notar que, à medida que aumenta a mesma, reduz-se a evaporação respiratória. 0 efeito da temperatura do ar sobre os dois tipos de evaporação também é diferente, conforme a espessura do velo, sendo mais acentuado quando o velo é menos espesso (7,5 a 8,1 cm), segundo Silva et al. (2003).

Silva et al. (2003), concluíram que a evaporação cutânea tem um papel importante para a termorregulação de ovinos lanígeros em ambientes de alta 
temperatura, contribuindo em média com $63 \%$ da evaporação total. Pois em ambientes tropicais a temperatura do ar tende a ser próxima ou eventualmente superior à corporal, tornando assim o fluxo de calor sensível (condução e convecção) ineficazes (Maia et al., 2005). Em adição, a temperatura radiante média do ambiente é geralmente superior à temperatura corporal dos animais, de modo que estes tendem antes a ganhar do que a perder energia por radiação (MAIA et al., 2005).

A tolerância ao calor e a adaptabilidade a ambientes tropicais e subtropicais são fatores importantes na produção ovina (BARBOSA et al., 1995) e características de pelame como a cor devem ser levadas em consideração na avaliação da tolerância ao calor (FINCH et al., 1984). Considera-se que uma capa de pelame escura apresenta maior absortividade da radiação solar de ondas curtas e, portanto, armazena maior quantidade de energia térmica, resultando em maior estresse para os animais do que os pelames claros (KAZAMA et al., 2008).

Observou-se que ovinos brancos tornaram-se hipertérmicos com TCI $(46,3)$ um pouco mais elevado que o obtido para os castanhos $(45,5)$ e pretos $(44,5)$. Esses valores podem ser considerados como críticos e demonstram melhor habilidade termorregulatória dos ovinos brancos (NEVES, et al., 2009). Ovinos de pelagem branca demonstraram ligeira superioridade na tolerância ao calor em relação aos castanhos e pretos, concluiu Neves et al. (2009).

A cor do pelame e suas características (espessura, número de fibras por área, diâmetro e comprimento do pêlo) podem afetar consideravelmente os mecanismos de troca térmica (HUTCHINSON \& BROWN, 1969; KOVARIK, 1973; CENA \& MONTEITH, 1975ab; FINCH et al., 1984; SILVA et al., 1988; MCARTHUR, 1991; SILVA, 1999).

\section{Respostas hormonais}

De acordo com Paes et al. (2000), os parâmetros sangüíneos têm sido utilizados mundialmente para avaliar o estado de saúde dos animais e também como indicadores de estresse calórico. 
Entre as alterações fisiológicas observadas, o estresse desencadeia o aumento dos níveis de adrenalina e do cortisol plasmático, entre outras reações endócrinas.

As glândulas adrenais e a tireóide desempenham importantes funções nesse mecanismo de adaptação (INGRAHAM et al., 1979; WEBSTER et al., 1991). Ruckebusch et al., 1991; Alnaimy et al., 1992; McFarlane et al., 1995, demonstraram que, sob altas temperaturas, na fase aguda do estresse térmico, ocorre elevação da concentração sangüínea de cortisol e redução na concentração dos hormônios tireoidianos, diminuindo a taxa de produção de calor metabólico (SANO et al., 1983; SALEM et al., 1991; McNABB, 1995; STARLING et al. 2005).

\subsection{Cortisol}

O estresse no animal ativa três respostas biológicas principais para reagir: o comportamento, o sistema nervoso autônomo e o sistema neuroendócrino. Os hormônios segregados pelo sistema neuroendócrino hipotálamo-hipófise têm um efeito persistente e duradouro, alterando o metabolismo, as competências imunológicas e o comportamento. Se o eixo HipotálamoHipófise-Adrenal é ativado pelo estresse é gerada uma cascata de mensagens hormonais provocando um aumento nas concentrações plasmáticas de cortisol.

No cérebro são iniciadas as respostas ao estresse como uma atividade neural integrada no hipotálamo, que produz hormônios específicos, no caso o hormônio liberador de corticotrofina ( $\mathrm{CRH}$ ) que regulam a atividade da adenohipófise, com posterior liberação de hormônio adrenocorticotrófico (ACTH) que irá resultar na secreção de hormônios glicorticóides pela adrenal.

O estresse ambiental, demonstrado pelas concentrações sangüíneas de cortisol, exerce efeitos pronunciados sobre várias características sangüíneas, hormonais e bioquímicas, os quais são necessários para o ajuste fisiológico de distintas funções orgânicas (NAZKI \& RATTAN, 1991). A secreção de cortisol estimula ajustes fisiológicos permitindo que um animal tolere o estresse causado por um ambiente quente (CHRISTISON \&JOHNSON, 1972). O cortisol 
plasmático pode aumentar em $20 \mathrm{~min}$. de exposição ao estresse térmico agudo, e alcançar um patamar de 2 h (CHRISTISON \&JOHNSON, 1972).

Em um trabalho com carneiros Ideal-Polwarth no município de Botucatu (SOUZA, M. I. L. et al., 2006) observou-se que o cortisol não apresentou um ritmo circadiano em suas concentrações, ao contrário daquilo que ficou definido nos animais estudados por SNOJ et al. (1994).

O trabalho de Nazki \& Rattan (1991) indicou concentrações plasmáticas de cortisol mais elevadas no inverno em relação às outras estações do ano, justificada pelo fato da estação de inverno, com sua temperatura mais fria, atuar como um fator estressor inespecífico, levando à liberação hipofisária de ACTH, com conseqüente aumento da atividade adrenal e da secreção de cortisol. Isso permitiu a adaptação dos animais ao ambiente adverso, pelas ações metabólicas deste hormônio, com relação à mobilização de reservas de energia e incremento da atividade celular. Contrariamente, STARLING et al. (2005), mantendo os animais em câmara bioclimática, observaram níveis de cortisol mais elevados na primavera e verão, atribuindo-os ao estresse da elevação da temperatura ambiente e do vapor de umidade, geradores de desconforto térmico e estresse, neste ambiente controlado.

Alguns autores demonstraram que, sob altas temperaturas, na fase aguda do estresse térmico, ocorrem elevação da concentração sangüínea de cortisol (RUCKEBUSCH et al., 1991; ALNAIMY et al., 1992; MCFARLANE et al., 1995).

\subsection{T3 e T4}

O lóbulo anterior da glândula pituitária produz o hormônio TSH, que atua principalmente sobre a glândula tireóide a produzir tiroxina (T4) e triiodotironina (T3). T3 é convertido a partir de T4 por desiodases em vários tecidos como fígado, rins, glândula pituitária, e tecido adiposo marrom (BIANCO \& LARSEN, 2005). Estes hormônios diferem-se e influencia os processos celulares, em particular a atividade da termogênese que representa cerca de $50 \%$ da taxa metabólica basal de animais normais (HABEEB et al., 
1992). Alguns fatores de estresse físico tendem a inibir a secreção da glândula tireóide (HABEEB et al., 1992).

Assim, entre as mudanças endócrinas importantes por ocasião do estresse, pode-se destacar também a diminuição na atividade do eixo hipotálamo-hipófise-tireóide, com redução das concentrações de hormônios tireoidianos (BIANCO \& KIMURA, 1999). Várias pesquisas indicam que a glândula tireóide é sensível ao estresse térmico, pelo fato de seus hormônios estarem ligados à termogênese, uma vez que aumentam a taxa metabólica, além de apresentarem ação potenciadora sobre as catecolaminas. Portanto, T3 e T4 podem apresentar níveis reduzidos em animais expostos a altas temperaturas, associados à menor produção de calor metabólico (JOHNSON et al., 1988).

Segundo Nascimento (1994), há necessidade também de se diferenciarem os efeitos de longa e curta duração do estresse pelo calor sobre os níveis circulantes de T3 e T4 em ruminantes, uma vez que a adaptação ao estresse crônico acarreta mudanças endócrinas que podem ser diferentes daquelas condicionadas pelo estresse momentâneo.

Em um trabalho desenvolvido com ovinos da raça Corriedale, durante a fase inicial do estresse pelo calor, foi verificado um aumento nos níveis hormonais de T3 e T4, sugerindo então que o estresse pelo calor produz mudanças nos níveis de T3 e especialmente, T4, ambos em magnitude e direção, de acordo com a duração da exposição (NASCIMENTO \& SILVA, 2000). Starling et al. (2005) concluíram que as concentrações séricas dos hormônios T3 e T4 e cortisol são afetadas pela temperatura e umidade do ar, se modo que, durante o estresse térmico, há uma resposta mais rápida do cortisol e maior período de latência nas respostas dos hormônios tireoidianos.

Em trabalho com bovinos foi detectada relação linear e negativa entre FR e os hormônios da tireóide, confirmando que, quando a termólise respiratória foi acionada em maior grau, tanto o T3 quanto o T4 diminuíram (MORAIS et al. 2008). No mesmo trabalho o autor concluiu que As concentrações de 
triiodotironina foram constantes ao longo do ano, enquanto as de tiroxina aumentaram na época seca e diminuíram na época chuvosa.

\section{Sistema nervoso}

Durante a reação de alarme, o chamado sistema nervoso autônomo (SNA) participa ativamente do conjunto das alterações fisiológicas. O SNA È um complexo conjunto neurológico que controla autonomamente todo o meio interno do organismo, através da ativação e da inibição dos diversos sistemas, vísceras e glândulas.

O sistema nervoso simpático também é ativado, estimulando a liberação de adrenalina e noradrenalina nos terminais nervosos simpáticos e na medula adrenal (DUKES, 1997). Os glicocorticóides, em conjunto com as catecolaminas, irão provocar alterações metabólicas visando mobilizar e fornecer energia para o organismo através da lipólise, da glicogenólise e da degradação de proteínas, dando subsídios para que o corpo possa restabelecer o equilíbrio (Gonzalez \& Silva, 2003).

Existe uma vasta fonte de informações que sugerem que o hipotálamo, em especial o núcleo supraquiasmático, é uma estrutura importante que regulamentam a um ritmo circadiano e sazonal da maioria das funções biológicas - a função reprodutiva e comportamento particularmente nos mamíferos (PANDO \& SASSONE-CORSI, 2001) - incluindo o estro e liberação tônica de hormônios e, em alguns casos o tamanho gonadal (BUIJS et al., 2003). Isto é devido ao fato de que há evidências sugerindo que o SCN é sensível às mudanças na temperatura ambiente, com algumas células são mais sensíveis ao frio e outros mais sensíveis ao calor, embora a variação fotoperiódica também pode ter uma influência forte (BURGOON \& BOULANT, 2001). O hipotálamo no cérebro, desempenha um papel central na termoregulação (EGAN et al.,2005). Especialmente, a área pré-óptia (PO) no hipotálamo é provavelmente a região mais importante. 


\section{Considerações finais}

O ambiente tropical, sobre tudo no semi-árido nordestino oferece elementos climáticos estressante aos ovinos afetando sua produção e reprodução, e os índices de conforto térmico estão para os ovinos fora da zona de conforto térmico durante todo o ano, levando os animais a alterar suas respostas fisiológicas com freqüência respiratório, e aumentar ou diminuir a secreção de hormônios envolvidos na homeotermia a fim de ajustar seu organismo ao estresse por calor, acarretando-se assim déficit produtivos. Portanto necessita-se selecionar e/ou desenvolver raças que melhor se adaptem as condições ambientas nos trópicos, assim como viabilizar condições ambientais para minimiza o estresse por calor.

\section{Referências bibliográficas}

ALNAIMY, A.; HABEeB, M.; FAYAZ, I. et al. Heat stress. In: PHILLIPS, C.; PIGGINS, D. (Eds.) Farm animals and the environment. Wallingford: CAB International, 1992. p.27-47.

ALEXANDER, G.; WILLIAMS, D. Temperature regulation in the newborn lamb. VI. Heat exchanges in lambs in a hot environment. Australian Journal of AgriculturalResearch, v.13, p.122-143, 1962.

AYOADE, J. O. Introdução à climatologia para os trópicos. 3. ed. Rio de Janeiro: Bertrand Brasil, 332 p., 1991.

BACCARI JÚNIOR, F. Métodos e técnicas de avaliação da adaptabilidade dos animais às condições tropicais. In: SIMPÓSIO INTERNACIONAL DE BIOCLIMATOLOGIA ANIMAL NOS TRÓPICOS, 1990, Fortaleza-CE. Anais... Brasília: EMBRAPA-DIE, p. 9-17, 1990.

BARBOSA, O. R.; MACEDO, F. A. F.; GROES, R. V.; GUEDES, J. M. F. Zoneamento bioclimático da ovinocultura no estado do Paraná. Revista Brasileira de Zootecnia, v. 30, n. 2, p. 454460, 2001.

BARBOSA, O. R.; SILVA. R. G.; SCOLAR, J.; GUEDES, J. M. F. Utilização de um índice de conforto térmico em zoneamento bioclimático da ovinocultura. Boletim da Indústria Animal, v. 52, n. 1, p. 37-47, 1995.

BIANCA, W.; KUNZ, P. Physiological reactions of three breedes of goats to cold, heat and hight altitude. Livestock production Science, [S.I.], v. 5, n. 1, p. 57-69, 1978.

BIANCO, A. C., \& LARSEN, P. R. Cellular and structural biology of the deiodinases. Thyroid, 15, 777-786, 2005.

BIANCO, A.C.; KIMURA, E.T. Fisiologia da glândula tireóide. In: AIRES, M.M. (Ed.) Fisiologia. Rio de Janeiro: Guanabara Koogan, 1999. p.812-828. 
BIRGEL JÚNIOR, E. H. et al. Valores de referência do eritrograma de bovinos da raça Jersey criados no Estado de São Paulo. Arquivo Brasileiro de Medicina Veterinária e Zootecnia, Belo Horizonte, v. 53, n. 2, p. 164-171, 2001.

BLIGH, J. The synchronous discharge of apocrine sweat glands of the Welsh mountain sheep. Nature, v.189, p.582-583, 1961.

BROOK, A.H.; SHORT, B.F. Regulation of body temperature of sheep in a hot environment. Australian Journal of Agricultural Research, v.11, p402-407, 1960a.

BROOK, A.H.; SHORT, B.F. Sweating in sheep. Australian Journal of Agricultural Research, v.11, p.557-569, 1960b.

BUFFINGTON, D. E.; COLLAZO-AROCHO, A.; CANTON, G. H. et al. Black globe-humidity index (BGHI) as comfort equation for dairy cows. Transactions of the ASE, Michigan, v.24, n.3, p. 711-714, 1981.

BUIJS,R.M., VANEDEN,C.G.,GONCHARUK,V.D.,KALSBEEK,A.The biological clock tunes the organs of the body: timing by hormones and the autonomic nervous system. J. Endocrinol. 177 (1), 17-26. 2003.

BURGOON, P.W., BOULANT, J.A. Temperature-sensitive properties of rat suprachiasmatic nucleus neurons. Am. J. Physiol. Regul. Integr. Comp. Physiol. 281 (3), R706-R715, 2001.

CENA, K.; MONTEITH J. L. Transfer processes in animal coats. 1. Radiative transfer. Proceedings of Royal Society of London Biological Sciences, London, v. 188, p. 377-393, 1975a.

CENA, K.; MONTEITH J. L.Transfer processes in animal coats. 3. Water vapour diffusion. Proceedings of Royal Society of London Biological Sciences, London, v.188, p. 413-423, 1975b.

CEZAR, M. F. et al. Avaliação de parâmetros fisiológicos de ovinos Dorper, Santa Inês e seus mestiços perante condições climáticas do trópico semi-árido nordestino. Ciênc. Agrotec., Lavras, v. 28, n. 3, p. 614-620, 2004.

CUNNINGHAM, J. G. KLEIN, B. G. Tratado de Fisiologia Veterinaria. 4a edição. Rio de Janeiro: Guanabara Koogan, 728p., 2008.

CURTO, F. P. F.; NAAS, I. A.; PEREIRA, D. F.; SALGADO, D. D. Estimativa do padrão de preferência térmica de matrizes pesadas (frango de corte). R. Bras. Eng. Agríc. Ambiental, v.11, n.2, p.211-216, 2007.

EGAN GF, JOHNSON J, FARRELL M, et al. Cortical, thalamic, and hypothalamic responses to cooling and warming the skin in awake humans: a positron-emission tomography study. Proc Natl Acad Sci USA 102, 5262-7. 2005.

ELVINGER, F.; NATZKE, R.; HANSEN, P. Interactions of heat stress and bovine somatotropin affecting physiology and immunology of lactating cows. Journal Dairy Science, Champaign, v. 75, p. 449-462, 1992.

FERNANDES , A. A. O. ; BUCHANAN, D.; SELAIVE-VILLARROEL, A. B. Avaliação dos Fatores Ambientais no Desenvolvimento Corporal de Cordeiros Deslanados da Raça Morada Nova. Rev. bras. zootec., v.30, p.1460-1465, 2001. 
FIALHO, T. E.; OST, P.R.; OLIVEIRA, V. Interações ambiente e nutrição - estratégias Nutricionais para ambientes quentes e seus Efeitos sobre o desempenho e Características de carcaça de suínos. II Conferência Internacional Virtual sobre Qualidade de Carne Suína Concórdia, SC, 2001.

FINCH, V. A.; BENNETT, I. L.; HOLMES, C. R. Coat color in cattle: effect of thermal balance, behaviour and growth and relationship with coat type. Journal of Agricultural Science, Cambridge, v. 102 p. 141-147, 1984.

FINCH, V.A. Heat as a stress factor in herbivores under tropical conditions. In: Gilchrist, F.M.C., Mackie, R.I. (Eds.), Herbivore Nutrition in the Subtropics and Tropics. The Science Press, Graighall, South Africa, pp. 89-105, 1984.

GOLDBERGER AL, PENG C-K, LIPSITZ LA. What is physiologic complexity and how does it changes with aging and disease? Neurobiol Aging.23:23-6,2002.

GONZALEZ, F. H. D.; SILVA, S. C. Introdução à bioquímica veterinária. 2.ed. Porto Alegre: UFRGS, 360 p., 2003.

GUYTON, A. C.; HALL, J. E.; Tratado de Fisiologia Médica. $11^{a}$ ed. Rio de Janeiro: Guanabara-Koogan, 1014p., 1997.

HAFEZ, E. S. E. Adaptacion de los animales domésticos. Ed. Labor S. A. Barcelona, Espanha, 563p., 1973.

HAFEZ, E.S.E., BADRELDIN, A.L., SHARAFELDIN, M.A. Heat tolerante studies of fat-tailed sheep in the tropics. J. Agric.Sci, 47(2):280-286, 1956.

HAHN, G. L. Management and housing of farm animals in hot environments. In: Stress Physiology in Livestock (M. K. Yousef, ed.), vol. II. Boca Raton, FL: CRC Press, 1985.

HALES, J.R.S. Physiological responses to heat. In: ROBERTSHAW, D. Ed.) Environmental physiology. London: Butterworths, 1974.

HOFMEYR, H.S.; GUIDRY, A.J.; WALTZ, F.A. Effects of temperature and wool length on surface and respiratory evaporative losses of sheep. Journal of Applied Physiology, v.26, p.517523, 1969.

HUTCHINSON, J. C. D.; BROWN, G. D. Penetrance of cattle coats by radiation. Journal of Applied Physiology, Bethesda, v. 26, p. 454-464, 1969.

JOCA, S. R. L.; PADOVAN, C. M.; GUIMARÃES, F. S. Stress depression and the hippocampus. Revista Brasileira de Psiquiatria, v. 25, v. 2, p 46-51, 2003.

JOHNSON, H. D.; LI, R.; MANALU, W.; SPENCER JOHNSON, K. J. Effects of somatotropin on milk yield and physiological responses during summer farm and hot laboratory conditions. Journal Dairy Science, Champaign, v. 74, p. 1250-1262, 1991.

JOHNSON, H.D.; KATTI, P.S.; HAHN, L. et al. Short-term heat acclimatation effects on hormonal profile of lactating cows. Research Bulletin. Missouri: University of Missouri, 30p., 1988.

KADZERE, M. R.; MURPHY, N.; SILANIKOVE, E.; MALTZ. Heat stress in lactating dairy cows: a review. Livestock Production Science, [S.I.], v. 77, p. 59-91, 2002.

KELLY, W. R. Diagnóstico clínico veterinário. México: Continental, 444 p., 1976. 
KNAPP, B.J.; ROBINSON, K.W. The role of water for heat dissipation by a Jersey cow and a Corriedale ewe. Australian Journal of Agricultural Research, v.5, p.568-577, 1954.

KOVARIK, M. Radiation penetrence of protective covers. Journal Applied Physiology, Bethesda, v. 35, p. 562-563, 1973.

LEDEZMA, J. J. H. Sheep. In: JOHNSON, E. Bioclimatology and the adaptation of livestock. Amsterdam: Elsevier, p. 169-179, 1987.

LEE, J. A.; ROUSSEL, J. D.; BEATTY, J. F. Effect of temperature season on bovine adrenal cortical function, blood cell profile, and milk production. Journal of Dairy Science, Champaign, v. 59, n. 1, p. 104-108, 1974.

LEMERLE, C., GODDARD, M.E. Assessment of heat stress in dairy cattle in Papua New Guinea. Anim. Health Prod. V.18, p. 232-242, 1986.

MAIA, A. S. C.; daSILVA, R. G.; LOUREIRO, C. M. B.. Sensible and Latent Heat Loss from the Body Surface of Holstein Cows in a Tropical Environment. Int. J. Biometeorol. (in press), 2005b.

MARTELLO, L. S.; SILVA J/NIOR, H. S.; SILVA, S. L.; TITTO, E. A. L. Respostas fisiológicas e produtivas de vacas holandesas em lactação submetidas a diferentes ambientes. Revista Brasileira de Zootecnia, v. 33, n. 1, p.181-191, 2004.

MCDOWELL, R.E., HOOVEN, N.W., CAMOENS, J.K. Effects of climate on performance of Holsteins in first lactation. J. Dairy Sci. 59, 965-973, 1976.

McFARLANE, A.; COGHLAN, J.; TRESHAM, J. et al. Corticotropin-releasing factor alone, but not arginine vasopressin alone, stimulates the release of adrenocorticotropin in the conscious intact sheep. Endocrinology, v.136, n.5, p.1821-1827, 1995.

MCLEAN, J. A.; CALVERT, D. T. Influence of air humidity on the partition of heat exchanges of cattle. Journal Agricultural Science, Cambridge, v. 78, p. 303, 1972.

MULLER, C. J. C.; BOTHA, J. A.; SMITH, W. A. Effect of shade on various parameteres of Friesian cows in a Mediterranean climate in South Africa: 3. behavior. South African Journal of Animal Science, Pretoria, v. 24, p. 61-66, 1994.

NASCIMENTO, M.R.B.M. Efeito da variação da temperatura ambiente sobre os níveis séricos de 3,5,3' triiodotironina (T3) e tiroxina (T4) em ovinos corriedale. Jaboticabal: Universidade Estadual Paulista, 1994. 44p. Dissertação (Mestrado em Zootecnia) Universidade Estadual Paulista, 1994.

NASCIMENTO, M.R.B.M. Níveis séricos de tiroxina (T4) e 3,5,3' triiodotironina (T3) relacionados ao efeito do mês, da ordem e do estágio de lactação em vacas das raças Holandesa e Guzerá. Jaboticabal: Universidade Estadual Paulista, 2002. 43p. Tese (Doutorado em Zootecnia) -Universidade Estadual Paulista, 2002.

NAZKI, A. R.; RATTAN, P. J. S. Some hormonal and biochemical characteristics of blood in sheep as related to different seasonal environments. Indian Veterinary Journal, v. 68, p.2832, 1991.

NeVes, M. L. M. W., AZeVedo, M. Costa, L. A. B. Guim, A. Leite, A. M. ChagAs, J. C. Níveis críticos do Índice de Conforto Térmico para ovinos da raça Santa Inês criados a pasto no agreste do Estado de Pernambuco. Acta Scientiarum. Animal Sciences, Maringá, v. 31, n. 2, p. 169-175, 2009. 
OLIVEIRA F. S. Termorregulação e adaptabilidade climática de ovinos sem padrão racial definido e da raça dorper na Sub-região Meio-Norte do Brasil. Teresina: 2007. 72f. Dissertação (Mestrado em Ciência Animal) - Universidade Federal do Piauí, Teresina, 2007.

PAES, P. R.; BARIONI, G.; FONTEQUE, J. R. Comparação dos valores hematológicos entre caprinos fêmeas da raça Parda Alpina de diferentes faixas etárias. Veterinária Notícias, Uberlândia, v. 6, n. 1, p. 43-49, 2000.

PANDO, M.P., SASSONE-CORSI, P., 2001. Signaling to the mammalian circadian clocks: in pursuit of the primary mammalian circadian photoreceptor. Sci. STKE (107), RE16, 2001.

PIRES, M. F. A.; TEODORO, R. L.; CAMPOS, A. T. Efeito do estresse térmico sobre a produção de bovinos. In: CONGRESSO NORDESTINO DE PRODUÇÃO DE RUMINANTES. RUMINANTES E NÃO RUMINANTES, 2., 2000, Teresina. Anais... Teresina: Sociedade Nordestina de Produção Animal, p. 87-105, 2000.

QUATERMAIN, A. R.; BROANBENT, M. P. Some patterns of response to climate by the Zambian goat. East African Agricultural and Forestry Journal, p. 115-124, July, 1974.

RIEK, P.F.; HARDY, M.H.; LEE, D.H.K. et al. The effect of the dietary plane upon the reactions of two breeds of sheep during short exposures to hot environments. Australian Journal of Agricultural Research, v.1, p.217-230, 1950.

SALEM, M.H.; EL-SHERBINY, A.A.; KHALIL, M.H. et al. Diurnal and seasonal rhythm in plasma cortisol, trodothyronine and thyronine as effected by the wool coat in Barki sheep. Indian Journal Animal Science, v.61, n.9, p.946-951, 1991.

SANO, H.; TAKAHASHI, K.; AMBO, K. et al. Turnover and oxidation rates of blood glucose and heat production in sheep exposed to heat. Journal Dairy Science, v.66, p.856-861, 1983.

SANTOS, F.C.B.; SOUSA, B.B.; ALFARO, C.E.P.; CÉSAR, M.F.; PIMENTA FILHO, E.C.; ACOSTA, A.A.A.; SANTOS, J.R.S. Adaptabilidade de caprinos exóticos e naturalizados ao clima semiárido do nordeste brasileiro. Ciência Agrotécnica, Lavras, v.29, n.1, p.142-149. 2005.

SANTOS, J. R. S.; SOUZA, B. B.; SOUZA, W. H.; CEZAR, M. F.; TAVARES, G. P. Avaliação da adaptabilidade de ovinos da raça santa inês, morada nova e mestiços de dorper, no semiárido. In: REUNIÃO ANUAL DA SOCIEDADE BRASILEIRA DE ZOOTECNIA, 40., 2003, Santa Maria, RS. Anais... Santa Maria: SBZ, p. 1-5, 2003.

SILVA, R. G. Estimativa do balanço térmico por radiação em vacas Holandesas expostas ao sol e á sombra em ambiente tropical. Revista Brasileira de Zootecnia, Viçosa, v. 28, n. 6, p. 1403-1411, 1999.

SILVA, R. G.; GONDIM, A. G. Comparação entre as raças Sindi e Jersey e seus mestiços, relativamente a tolerância ao calor na região Amazônica. Pesquisa Agropecuária Brasileira, Brasília, v. 6, p. 37-44, 1971.

SILVA, R.G.; COSTA, M.J.R.P.; NOGUEIRA, O.R. Sweating rate of heat stressed sheep. In: INTERNATIONAL CONGRESS OF BIOMETEOROLOGY, 12., 1990, Viena. Proceedings... Viena: International Society of Biometeorology, p.64, 1990.

SILVA, R.G.; STARLING, J.M.C. Evaporação Cutânea e Respiratória em Ovinos sob Altas Temperaturas Ambientes. R. Bras. Zootec., v.32, n.6, (Supl. 2), p.1956-1961, 2003. 
SILVA,R.G.; BARBOSA,O,R. Thermal confort índex for sheep. Proc. $13^{\circ}$ International Congess of Bioclimatology, September 12- 18, Calgary, Canada, vol.2, p.383-392, 1993.

SILVA. R. G.; ARANTES NETO, J. G.; HOLTZ -FILHO, S. V. Genetic aspects of the variation of the sweating rate and coat characteristics of Jersey cattle. Brazilian Journal of Genetics, Ribeirão Preto, v. 11, p. 335-347, 1988.

SINGH, K.; BHATTACHARYYA, N. K. Cardiorespiratory activity in Zebu and their F crosses with European breeds of dairy cattle at different ambient temperatures. Livestock Production Science, [S.I.], v. 24, p. 119-128, 1990.

SIQUEIRA, E.R. Estudo da produção, correlações fenotípicas e repetibilidade das características da lã em cinco raças de ovinos no sitema intensivo de pastejo. Jaboticabal, SP, 1990.121p. Tese (Doutorado em Zootecnia) - Faculdade de Ciências Agrárias e Veterinárias, Universidade Estadual Paulista, 1990.

SOUZA, B. B. et al. Comportamento fisiológico de ovinos deslanados no semi-árido expostos em ambiente de sol e em ambiente de sombra. Veterinária e Zootecnia, São Paulo, v. 2, p. 1-7, 1990.

SOUZA, D.E.; SOUZA, B.B.; SOUZA, W.H.; CEZAR, M.F.; SANTOS, J.R.S.; TAVARES, G.P. Determinação dos parâmetros fisiológicos e gradiente térmico de diferentes grupos genéticos de caprinos no semi-árido. Ciência Agrotécnica, Lavras, v.29, n.1, p.177-184. 2005.

STARLING, J. M. C.; SILVA, R.G..; NEGRÃO, J.A.; MAIA, A.S.C.; BUENO, A.R. Variação estacional dos hormônios tireoideanos e do cortisol em ovinos em ambiente tropical. Revista Brasileira de Zootecnia, Viçosa, v. 34, p. 2064-2073, 2005.

THOM, E.C. Cooling degree: day air conditioning, heating, and ventilating. Transactions Amer. Soc. Heating, Refrigeratiing and Air-Condioning Engrs. v. 55, p. 65-72, 1958.

YOUSEF, M. K. Stress physiology in livestock. Boca Ratton: CRC, P. 217, 1985. 